\section{Kidney \\ Blood Pressure Research}

Kidney Blood Press Res 2014;39:420-426

DOI: 10.1159/000368455

Published onlıne: November 12, 2014

Accepted: September 01, 2014

The Access article licensed under the terms of the Creative Commons Attribution-

\title{
Correlation Between Endothelial Dysfunction and Left Ventricular Remodeling in Patients with Chronic Kidney Disease
}

\author{
Tao Peng Zhao Hu Ling Wu Dengren Li Xiangdong Yang \\ Department of Nephrology, Shandong University Qilu Hospital, Jinan 250012, China
}

\section{Key Words}

Chronic kidney disease - Endothelin-1 - Nitric oxide - Inducible nitric oxide synthase • Ventricular remodeling

\begin{abstract}
Background/Aims: To investigate the role of endothelial dysfunction on left ventricular remodeling in patients with chronic kidney disease and to evaluate the correlation between endothelial dysfunction and left ventricular remodeling. Methods: Seventy-three patients with chronic kidney disease as study-group and thirty healthy volunteers as control-group were enrolled in the present study. All patients in both groups had echocardiography examination. The concentration of endothelin-1, nitric oxide, and inducible nitric oxide synthase of serum of all patients and healthy volunteers was measured. The incidence of cardiac structural abnormalities in patients with chronic kidney disease, and the relationship between endothelial dysfunction and cardiac structural abnormalities were analyzed. Results: The incidence of left ventricular hypertrophy, left ventricular concentric remodeling, and left ventricular systolic dysfunction was $65 \%, 8.33 \%$, and $16.67 \%$, respectively. The level of endothelin-1 and nitric oxide increased in study-group, and the concentration of inducible nitric oxide synthase decreased. There was significant positively relationship between plasma endothelin-1 and left ventricular mass index, interventricular septal thickness, left ventricular diastolic diameter. There was negatively relationship between the level of serum nitric oxide and the maximum flow velocity at the mitral in left ventricular diastolic stage. There was not any correlation between inducible nitric oxide synthase with left ventricular remodeling. Conclusions: The results showed that there was a higher incidence of left ventricular hypertrophy in patients with chronic kidney disease. Endothelin-1 and nitric oxide played an important role on the development of left ventricular hypertrophy.
\end{abstract}

Copyright @ 2014 S. Karger AG, Basel

Tao Peng and Xiangdong Yang contributed equally and thus sharing corresponding authorship.

Tao Peng \& Xiangdong Yang

Department of Nephrology, Shandong University Qilu Hospital, 107 Wenhua Xi Road, Jinan, Shandong Province, 250012 (P. R. China), Tel. +86-531-8216-9316

E-mail: sesame_oil@126.com 


\section{Kidney Blood Pressure Research}

\begin{tabular}{l|l}
\hline Kidney Blood Press Res 2014;39:420-426 \\
\hline DOI: $10.1159 / 000368455$ & (c) 2014 S. Karger AG, Basel
\end{tabular}

Published onIIne: November 12, 2014

www.karger.com/kbr

Peng/Hu/Wu/Li/Yang: Endothelial Dysfunction and Ventricular Remodeling in CKD

\section{Introduction}

Chronic kidney disease (CKD) is common and associated with an increased risk of cardiovascular disease. CKD is now recognized as an independent risk factor for coronary artery disease (CAD) in community-based studies as well as in high cardiovascular (CV) risk populations [1-3]. Data from prospective studies showed that cardiovascular diseases (CVD) is the common and severely complication of chronic kidney disease, which is the most cause of morbidity and mortality in patients with CKD and end-stage renal disease (ESRD), whether receiving hemodialysis (HD) or peritoneal dialysis (PD). Cardiovascular diseases includes not only obstructive CAD, but also other diseases, such as chronic heart failure, arrhythmia, and sudden death. The main factors involving in cardiovascular disease are age, diabetes mellitus, hypertension, malnutrition, and chronic inflammation, which accelerate atherosclerosis, make vascular endothelial dysfunction and coronary artery calcification, thus left ventricular structural and functional abnormalities appear, including the left ventricular hypertrophy, left ventricular concentric remodeling, and left ventricular systolic dysfunction, which called left ventricular remodeling associated with chronic kidney disease.

The endothelial cells plays a crucial role in controlling homeostasis and vascular tone by many vasoactive factors coming from the endothelial cells [4]. In many disease associated cardiovascular disease, endothelial cell dysfunction plays an important role in the cardiovascular morbidity and mortality. In fact, the mechanism of endothelial dysfunction needs to be investigated deeply. The role of a decrease in nitric oxide (NO) and increase in end othelin-1 (ET-1) were thought to be one of the important mechanisms and manifestations of endothelial dysfunction in many diseases [5-7], including CKD [8].

In the present study, we measured the plasma level of endothelin-1, nitric oxide and inducible nitric oxide synthase to observe the changes of endothelial dysfunction in patients with CKD, and to compare the correlation between endothelial dysfunction and left ventricular remodeling in patients with CKD.

\section{Materials and Methods}

\section{CKD patients and healthy volunteers}

A total of 73 patients with CKD as study-group ( 39 male and 34 female, mean age: $43.6 \pm 7.4$ years) were enrolled into the present study, and examined at the department of nephrology, Shandong university Qilu hospital, Shandong province, China, between March 2012 and November 2013. All cases enrolled were diagnosed as chronic kidney disease (CKD) by clinical presentation, laboratory data, and imaging manifestations according to the glomerular filtration rate (GFR) [9]. All enrolled patients in the study-group were divided into three sub-groups according the GFR: stage 3, 26 cases GFR $30 \sim 60 \mathrm{ml} / \mathrm{min} / 1.73 \mathrm{~m}^{2}$; stage 4, 23 cases GFR $15 \sim 29 \mathrm{ml} / \mathrm{min} / 1.73 \mathrm{~m}^{2}$ and stage 5,24 cases GFR $<15 \mathrm{ml} / \mathrm{min} / 1.73 \mathrm{~m}^{2}$.

All enrolled subjects in study-group were notyounger than 18 years and had primary diseases, including chronic glomerulonephritis (23 cases, 31.5\%), diabetic nephropathy (15 cases, 20.5\%). hypertensive renal damage (12 cases, $16.4 \%$ ), chronic interstitial nephritis ( 4 cases, $5.5 \%$ ), polycystic kidney disease (2 cases, $2.7 \%$ ) and unknown cause (17 cases, $23.3 \%$ ).

A total of 30 healthy volunteers without chronic kidney disease as control-group (18 male and 12 female, mean age: $41.9 \pm 8.3$ years) were enrolled in the present study and examined from the same department from March 2012 and November 2013. Enrolled cases in control-group with GFR of over $90 \mathrm{ml} /$ $\mathrm{min} / 1.73 \mathrm{~m}^{2}$ were all over 18 years and had no diagnosis of chronic glomerulonephritis, diabetes mellitus, hypertensive renal damage, liver dysfunction, dyslipoproteinemia, chronic interstitial nephritis, polycystic kidney disease, asthma or allergic rhinitis.

The study protocol was approved by the ethics committee of Shandong University Qilu Hospital, and written informed consent was obtained from all patients after they reviewed a written summary of the study plan. All patients gave informed written consent for analysis of their tissue for research purposes. 


\section{Kidney \\ Blood Pressure Research}

Kidney Blood Press Res 2014;39:420-426

\begin{tabular}{l|l}
\hline DOI: $10.1159 / 000368455$ & C 2014 S. Karger AG, Basel
\end{tabular}

Published onIIne: November 12, 2014

www.karger.com/kbr

Peng/Hu/Wu/Li/Yang: Endothelial Dysfunction and Ventricular Remodeling in CKD

Reagents

Nitric oxide and inducible nitric oxide synthase kit came from the Nanjing jiancheng bioengineering institute and endothelin kit came from the institute of radiation immunity in technology development center of PLA general hospital. All patients were processed by doppler echocardiograph (HP Sonos 5500).

\section{Methods}

All patients were processed for measuring left ventricular end diastolic diameter (LVDd), interventricular septum thickness (IVST), and left ventricular posterior wall thickness (LVPWT) by Doppler echocardiograph (HP Sonos 5500) through standard parasternal left ventricular long axis view. The peak velocity ratio of early diastolic to late diastolic (E/A) in mitral valve part was measured through apical four-chamber view. Left ventricular ejection fraction (LVEF) was calculated by biplane Simpson`s law. Left ventricular mass (LVM), left ventricular mass index (LVMI) and relative wall thickness (RWT) were calculated by Devereux correction formula [10]. All enrolled patients were measured height $(\mathrm{H}, \mathrm{cm})$, weight (W, kg), systolic blood pressure (SBP), diastolic blood pressure (DBP), hemoglobin (Hgb), and age at the admission of the present study. Body surface area (BSA) was calculated by formula as follows.

$$
\begin{aligned}
& \mathrm{LVM}(\mathrm{g})=0.8 \times\left\{1.04 \times\left[(\mathrm{LVDd}+\mathrm{IVST}+\mathrm{LVPWT})^{3}-\mathrm{LVDd}^{3}\right]\right\}+0.6 \\
& \mathrm{LVMI}\left(\mathrm{g} / \mathrm{m}^{2}\right)=\mathrm{LVM} / \mathrm{BSA} \\
& \mathrm{BSA}=0.0061 \times \mathrm{H}+0.0128 \times \mathrm{W}-0.1529 \\
& \mathrm{RWT}=2 \mathrm{LVPWT} / \mathrm{LVDd}
\end{aligned}
$$

The endothelin-1 (ET-1) (by Radioimmunoassay), blood urea nitrogen (BUN), serum creatinine (Scr) and blood route (BR) were measured in the morning fasting cubital vein $8 \mathrm{ml}$ from all cases. Glomerular filtration rate (GFR) was calculated by using the Modification of Diet in Renal Disease (MDRD) [11].

The nitric oxide(NO) was measured by Nitrate reductase, because the half-life of NO in vivo is very short (about a few seconds), we can not measure the concentration of NO in serum directly. NO in serum will soon be metabolized to nitrate / nitrite $\left(\mathrm{NO}_{2}^{-} / \mathrm{NO}_{3}^{-}\right)$, so we can measure the metabolites to reflect the serum NO. The serum $\mathrm{NO}_{3}^{-}$is reduced to $\mathrm{NO}_{2}^{-}$by nitrate reductase, and the NO was measured according to the principle that the reaction of Griess reagent with $\mathrm{NO}_{2}^{-}$can product some colored azo substances. The colored azo substances was absorbed maximally at $540 \sim 560 \mathrm{~nm}$ wavelength, and we measured their absorbance values to get the concentration of serum NO, the linear regression equation is $Y=120.8 X-2.2, r=0.9975$.

The inducible nitric oxide synthase (iNOS) was measured by Double-antibody sandwich, the principle is that the purified monoclonal antibodies-coated microtiter plate is made to solid-phase antibody. The product is added to microtiter plate, and then with HRP-labeled antibody to form an antibody - antigen enzyme-antibody complex, after washing completely, add TMB as chromogenic substrate. TMB is conversed to blue by HRP enzyme-catalyzed, and then conversed to the final yellow at role of acid. Color depth is positively correlated with sample. Then absorbance (OD) at $450 \mathrm{~nm}$ wavelength is measured by enzymelabeled instrument, then we can calculate the concentration of the sample products via a standard curve.

\section{Outcome criteria}

We used echocardiography normal reference from Ruijin Hospital, Shanghai Second Medical University, Institute of Hypertension. Normal standard of LVDd, IVST, and LVPWT was 40 60mm, 6-11mm, and $6-11 \mathrm{~mm}$, respectively. $\mathrm{EF}<50 \%$ and $\mathrm{E} / \mathrm{A}<1$ are diagnosed as the left ventricular systolic dysfunction and left ventricular diastolic dysfunction. For male and female, the diagnostic standard of left ventricular hypertrophy is different, male is $\mathrm{LMVI} \geq 135 \mathrm{~g} / \mathrm{m}^{2}$, female is $\mathrm{LVMI} \geq 111 \mathrm{~g} / \mathrm{m}^{2}$. RWT $>0.45$ was the standard of cardiac enlargement [12].

\section{Statistical analysis}

Data were expressed as mean \pm SD. Statistical analysis was evaluated using SPSS for Windows 16.0 software, followed by one-way analysis of variance and the $q$-test to assess the significance of the differences among the various groups. Correlation analysis were assessed by linear regression analysis. Significance was determined at $P<0.05$. 


\section{Kidney Blood Pressure Research}

Table 1. The level of ET-1, NO and iNOS $(\bar{x} \pm \mathrm{s})$

\begin{tabular}{lccc}
\hline Group & ET- $1\left(\rho / \mathrm{ng} \cdot \mathrm{L}^{-1}\right)$ & NO $\left(c / \mu \mathrm{mol} \cdot \mathrm{L}^{-1}\right)$ & iNOS $\left(c / \mu \mathrm{mol} \cdot \mathrm{L}^{-1}\right)$ \\
\hline Control & $59.94 \pm 14.88$ & $70.72 \pm 23.01$ & $29.80 \pm 4.62$ \\
Stage 3 & $163.71 \pm 39.91^{*}$ & $161.80 \pm 33.11^{*}$ & $24.27 \pm 3.76^{*}$ \\
Stage 4 & $203.03 \pm 21.12^{*}$ & $164.08 \pm 29.18^{*}$ & $23.98 \pm 4.01^{*}$ \\
Stage 5 & $251.30 \pm 30.21^{* *}$ & $179.27 \pm 40.79^{*}$ & $22.61 \pm 3.87^{*}$ \\
\hline${ }^{*} p<0.01$ vs. Control group; ${ }^{* *} p<0.01$ vs. Stage 3 & \\
\hline
\end{tabular}

Table 2. Comparison in echocardiographic indicators $(\bar{x} \pm s)$

\begin{tabular}{lcccc}
\hline & Control & Stage 3 & Stage 4 & Stage 5 \\
\hline LVDd $(\mathrm{d} / \mathrm{mm})$ & $42.14 \pm 4.23$ & $43.10 \pm 5.21$ & $47.27 \pm 5.89^{*}$ & $49.46 \pm 5.51^{* *}$ \\
IVST $(\delta / \mathrm{mm})$ & $10.27 \pm 0.67$ & $11.31 \pm 2.03$ & $12.91 \pm 1.79^{*}$ & $13.76 \pm 1.73^{*}$ \\
$\mathrm{LVPWT}(\delta / \mathrm{mm})$ & $9.61 \pm 0.70$ & $10.48 \pm 1.98$ & $12.03 \pm 3.11$ & $13.51 \pm 1.63$ \\
$\mathrm{LVMI}\left(\mathrm{g} / \mathrm{m}^{2}\right)$ & $95.24 \pm 38.67$ & $137.26 \pm 39.18^{*}$ & $163.11 \pm 47.08^{*}$ & $187.16 \pm 45.14^{* *}$ \\
$\mathrm{EF}(\%)$ & $0.64 \pm 0.09$ & $0.60 \pm 0.10$ & $0.57 \pm 0.13$ & $0.55 \pm 0.11^{*}$ \\
$\mathrm{E} / \mathrm{A}$ & $1.47 \pm 0.33$ & $1.19 \pm 0.41$ & $1.01 \pm 0.31^{*}$ & $0.82 \pm 0.27^{*}$ \\
\hline${ }^{*} p<0.01$ vs. Control group; ${ }^{* *} p<0.01$ vs. Stage 3 & & \\
\hline
\end{tabular}

\section{Results}

Left ventricular anomaly structure and dysfunction

In the present study, the manifestation of echocardiography in study-group 73 patients included the left ventricular hypertrophy (47 patients, 65\%), left ventricular eccentric hypertrophy (13 cases, 18.33\%), left ventricular concentric hypertrophy ( 34 patients, $46.67 \%$ ), left ventricular concentric remodeling (6 patients, 8.33\%), and normal structure ( 20 patients, $26.67 \%$ ).

In all study-group, 56 patients (76.67\%) had ventricular diastolic dysfunction, and left ventricular systolic dysfunction was seen in 12 patients $(16.67 \%)$. Fifty-three patients $(72.6 \%)$ showed not only left ventricular diastolic dysfunction, but also left ventricular hypertrophy or left ventricular concentric remodeling. Only 3 patients showed a kind of abnormal structure in cardiac ultrasound. The above study demonstrated that left ventricular diastolic dysfunction occurs early than cardiac structural changes of ultrasound in patients with CKD.

The level of ET-1, NO, and iNOS

The level of ET-1 and NO elevated in patients with CKD stage 3-5, and there was a signifecant difference between control-group and study-group $(p<0.01)$. The serum iNOS did not significantly decreased in CKD compared with control-group (Table 1).

Comparison in echocardiographic indicators

There were significant difference between patients with CKD stage 3-5 and controlgroup in every echocardiographic indicators. With the progression of renal failure, cardiac structure and function also deteriorated (Table 2).

Correlation analysis of NO, iNOS, ET-1, and left ventricular changes

Plasma ET-1 positively correlated with LVMI, IVST, and LVDd, but there was no statistical 


\section{Kidney \\ Blood Pressure Research}

significance correlation between the plasma ET-1 and LVPWT, EF, and E/A (Table 3). The level of NO in serum was negative correlated with the $\mathrm{E} / \mathrm{A}$, but the phenomenon disappeared between NO and LVMI, IVST, LVDd, and EF (Table 4). There was not any correlation between iNOS and echocardiographic indexes (Table 5).

\section{Multivariate regression analysis}

A multivariate regression analysis was performed to identify the most important factors affecting LVMI. LVMI was analyzed as the dependent variable, EI-1, BUN, Scr, SBP, $\mathrm{DBP}, \mathrm{Hgb}$, and age as independent variables. The BUN, Scr, DBP, Hgb, and age were excluded, we can get a linear model,which showed that LVMI was closely associated with SBP and ET-1 (Table 6). Partial correlation analysis was performed between ET-1 and SBP, the partial correlation coefficient was given to analyze the correlation between ET-1 and SBP (Table 7).

\section{Discussions}

Chronic kidney disease (CKD) is a major public health problem worldwide. Cardiovascular disease continues to be a common complication and be the leading cause of morbidity and mortality among people with CKD [13]. The rates of cardiovascular events and mortality consistently increase as kidney function declines [14]. Approximately 50\% of patients die from these lesions. The left ventricular hypertrophy has a high incidence in all cardiovascular complication. In the present study, $65 \%$ of patients with CKD had left ventricular hypertrophy, which was similar to those reported in literature [15-16]. Ha SK once reported that in 62 cases with chronic renal failure, the incidence of concentric hypertrophy, eccentric hypertrophy, concentric remodeling, and the normal structure were 56.5\%, 30.5\%,
Table 3. Correlation analysis of ET-1 and left ventricular changes

\begin{tabular}{lccc}
\hline$x$ & $y$ & $r$ & $P$ \\
\hline ET-1 & LVDd & 0.331 & 0.029 \\
ET-1 & IVST & 0.429 & 0.001 \\
ET-1 & LVPWT & 0.254 & 0.110 \\
ET-1 & LVMI & 0.494 & 0.000 \\
ET-1 & EF & 0.36 & 0.824 \\
ET-1 & E/A & -0.013 & 0.935 \\
\hline
\end{tabular}

Table 4. Correlation analysis of NO and left ventricular changes

\begin{tabular}{lccc}
\hline$x$ & $y$ & $r$ & $P$ \\
\hline NO & LVDd & 0.215 & 0.100 \\
NO & IVST & 0.097 & 0.460 \\
NO & LVPWT & 0.054 & 0.738 \\
NO & LVMI & 0.225 & 0.062 \\
NO & EF & -0.050 & 0.758 \\
NO & E/A & -0.316 & 0.044 \\
\hline
\end{tabular}

Table 5. Correlation analysis of iNOS and left ventricular changes

\begin{tabular}{lccc}
\hline$x$ & $y$ & $r$ & $P$ \\
\hline iNOS & LVDd & 0.102 & 0.526 \\
iNOS & IVST & 0.041 & 0.800 \\
iNOS & LVPWT & 0.071 & 0.657 \\
iNOS & LVMI & 0.007 & 0.960 \\
iNOS & EF & 0.018 & 0.910 \\
iNOS & E/A & -0.030 & 0.852 \\
\hline
\end{tabular}

Table 6. Multivariate regression analysis

Table 7. Partial correlation analysis

\begin{tabular}{lccc}
\hline Regression equation & $R^{2}$ & $F$ & $P$ \\
\hline LVMI = - 53.475+1.026 $\times \mathrm{SBP}+0.343 \times \mathrm{ET}$ & 0.400 & 12.659 & 0.000 \\
\hline
\end{tabular}

\begin{tabular}{|c|c|c|}
\hline Regression equation & Partial correlation coefficient & $P$ \\
\hline $\operatorname{SBP}(P / m m H g)$ & 0.3557 & 0.006 \\
\hline ET-1 $\left(\rho / \mathrm{ng} \cdot \mathrm{L}^{-1}\right)$ & 0.3576 & 0.005 \\
\hline
\end{tabular}




\section{Kidney \\ Blood Pressure Research}

$6.5 \%$, and $6.5 \%$, respectively [17]. In the present study, the proportion was $46.67 \%, 18.33 \%$, $8.33 \%$, and $26.67 \%$. The difference between both studies may be related to the different conditions and criteria selected.

Endothelin-1 is an important vasoactive factor secreted from blood vessels, the plasma level of which elevated in chronic heart dysfunction and chronic kidney dysfunction. ET-1 is proportional to the degree of deterioration of the disease and it can stimulate cultured cardiac fibroblast to grow, promote collagen to synthesize, be involved in cardiac hypertrophy. Endothelin-1 can also activate the local renin-angiotensin-aldosterone (RAA) system, promote platelet-derived growth factor (PDFG), transforming growth factor (TGF) synthesis and release, indirectly promote myocardial cell proliferation, lead to cardiac hypertrophy. Left ventricular hypertrophy is an important complication of chronic kidney disease, and there was a significant positive correlation between elevated plasma endothelin-1 and LVMI. As seen in Table 4, after adjusting the regression equation by systolic blood pressure, it can prove that ET-1 induced ventricular hypertrophy non-dependent of blood pressure [18].

In patient with $\mathrm{CKD}$, different serum nitric oxide levels lead to different results in different reports. The present study demonstrated that serum levels of NO increased with worsening renal function, but this phenomenon disappears for iNOS. Elevated levels of NO is a compensatory mechanism in CKD patients. NO, which is a vascular-derived relaxing factor, can stimulate cyclic guanosinc monophosphate (cGMP) generating, inhibit the expression of AngII and ET-induced protein kinase C (PKC), activate the expression of c-fos protooncogene in myocardial cells, thereby prevent the proliferation of cardiac myocytes and cardiac hypertrophy [19]. This study showed that serum level of NO was correlated with E/A, but not correlated with LVMI, LVDd, IVST, LVPWT, and EF.

\section{Conclusion}

There is a high incidence of left ventricular hypertrophy in patients with chronic kidney disease, and left ventricular diastolic abnormalities occur earlier than the clinical systolic dysfunction. ET-1 plays a non-blood pressure-dependent effects on inducing left ventricular hypertrophy, which has certain practical significance for prevention of cardiovascular complications of chronic kidney disease. NO, as a vasodilator activity factor, also plays an important role in the onset and progression of chronic kidney disease.

\section{Disclosure Statement}

None declared.

\section{Acknowledgement}

All authors express their appreciation to the enrolled patients. This study was supported by Shandong Province Outstanding Young Scientist Research Award Fund Project, NO. BS2013YY042. Natural Science Foundation of Shandong Province, No. ZR2013HM106.

\section{References}

1 Moradi H, Sica DA, Kalantar-Zadeh K: Cardiovascular burden associated with uremic toxins in patients with chronic kidney disease. Am J Nephrol 2013;38:136-148. 


\section{Kidney \\ Blood Pressure Research}

Kidney Blood Press Res 2014;39:420-426

\begin{tabular}{l|l}
\hline DOI: $10.1159 / 000368455$ & (C) 2014 S. Karger AG, Basel
\end{tabular}

Published onIIne: November 12, 2014

www.karger.com/kbr

2 Afsar B, Turkmen K, Covic A, Kanbay M: An Update on Coronary Artery Disease and Chronic Kidney Disease. Int J Nephrol 2014;2014:767424.

-3 Blood Pressure Lowering Treatment Trialists' Collaboration, Ninomiya T, Perkovic V, Turnbull F, Neal B, Barzi F, Cass A, Baigent C, Chalmers J, Li N, Woodward M, MacMahon S: Blood pressure lowering and major cardiovascular events in people with and without chronic kidney disease: meta-analysis of randomised controlled trials. BMJ 2013;347:f5680.

-4 Aghajanian A, Wittchen ES, Allingham MJ, Garrett TA, Burridge K: Endothelial cell junctions and the regulation of vascular permeability and leukocyte transmigration. J Thromb Haemost 2008;6:1453-1460.

5 Prieto D, Contreras C, Sanchez A: Endothelial dysfunction, obesity and insulin resistance. Curr Vasc Pharmacol 2014;12:412-426.

-6 Toda N, Nakanishi S, Tanabe S: Aldosterone affects blood flow and vascular tone regulated by endotheliumderived NO: therapeutic implications. Br J Pharmacol 2013;168:519-533.

7 Thorin E, Webb DJ: Endothelium-derived endothelin-1. Pflugers Arch 2010;459:951-958.

- 8 u J, Feng B, Ye Z, Yuan F, Zeng W, Luo Z, Qi W: Visfatin is related to lipid dysregulation, endothelial dysfunction and atherosclerosis in patients with chronic kidney disease. J Nephrol 2011;24:177-184.

$\checkmark 9$ Eknoyan G: Chronic kidney disease definition and classification: no need for a rush to judgment. Kidney Int 2009;75:1015-1018.

10 Devereux RB, Casale PN, Hammond IW, Savage DD, Alderman MH, Campo E, Alonso DR, Laragh JH: Echocardiographic detection of pressure-overload left ventricular hypertrophy: effect of criteria and patient population. J Clin Hypertens 1987;3:66-78.

11 Hallan S, Asberg A, Lindberg M, Johnsen H: Validation of the Modification of Diet in Renal Disease formula for estimating GFR with special emphasis on calibration of the serum creatinine assay. Am J Kidney Dis 2004;44:84-93.

12 Palmieri V, Okin PM, de Simone G, Bella JN, Wachtell K, Gerdts E, Boman K, Nieminen MS, Dahlöf B, Devereux RB: Electrocardiographic characteristics and metabolic risk factors associated with inappropriately high left ventricular mass in patients with electrocardiographic left ventricular hypertrophy: the LIFE Study. J Hypertens 2007;25:1079-1085.

13 Feng S, Jiang L, Shi Y, Shen H, Shi X, Jin D, Zeng Y, Wang Z: Uric Acid levels and all-cause mortality in peritoneal dialysis patients. Kidney Blood Press Res 2013;37:181-189.

14 The Global Burden of Metabolic Risk Factors for Chronic DiseasesCollaboration: Cardiovascular disease, chronic kidney disease, and diabetes mortality burden of cardiometabolic risk factors from 1980 to 2010: a comparative risk assessment. Lancet Diabetes Endocrinol 2014;2:634-647.

15 Peterson GE, de Backer T, Contreras G, Wang X, Kendrick C, Greene T, Appel LJ, Randall OS, Lea J, Smogorzewski M,Vagaonescu T, Phillips RA; African American Study of Kidney Disease Investigators: Relationship of left ventricular hypertrophy and diastolic function with cardiovascularand renal outcomes in African Americans with hypertensive chronic kidney disease. Hypertension 2013;62:518-525.

- 16 Unsal A, Kose Budak S, Koc Y, Basturk T, Sakaci T, Ahbap E, Sinangil A: Relationship of Fibroblast Growth Factor 23 with Left Ventricle Mass Index and Coronary Calcificaton in Chronic Renal Disease. Kidney Blood Press Res 2012;36:55-64.

17 Ha SK, Park HS, Kim SJ, Park CH, Kim DS, Kim HS: Prevalence and patterns of left ventricular hypertrophy in patients with predialysis chronic renal failure. J Korean Med Sci 1998;13:488-494.

- 18 Dhaun N, Moorhouse R, MacIntyre IM, Melville V, Oosthuyzen W, Kimmitt RA, Brown KE, Kennedy ED, Goddard J, Webb DJ: Diurnal Variation in Blood Pressure and Arterial Stiffness in Chronic Kidney Disease: The Role of Endothelin-1. Hypertension 2014;64:296-304.

19 Moningka NC, Tsarova T, Sasser JM, Baylis C: Protective actions of nebivolol on chronic nitric oxide synthase inhibition-induced hypertension and chronic kidney disease in the rat: a comparison with angiotensin II receptor blockade. Nephrol Dial Transplant 2012;27:913-920. 